Jurnal Ilmu Ilmu Agribisnis: Journal of Agribusiness Science, 9(2), Mei 2021

\title{
ANALISIS EFISIENSI PRODUKSI DAN PENDAPATAN USAHATANI PADI SAWAH DI KECAMATAN BALIGE KABUPATEN TOBA SAMOSIR
}

\author{
(Analysis of production's efficiency and income of rice paddy farming \\ in Balige Sub-district Toba Samosir Regency)
}

Natha Marwin, Wan Abbas Zakaria, Suriaty Situmorang

\begin{abstract}
Jurusan Agribisnis, Fakultas Pertanian, Universitas Lampung, Jl. Prof. Dr. Soemantri Brojonegoro No. 1, Bandar Lampung, 35145.e-mail: wanabas.zakaria@fp.unila.ac.id
\end{abstract}

\begin{abstract}
The study aims to identify the factors that affect lowland rice production, analyze the efficiency of using the production factors of the farming, and calculate the farmers' income of the farming in Balige Sub-district Toba Samosir Regency. The research was conducted in Hutagaol Peatalun Village and Hinalang Bagasan Village with 64 respondents. Farmer respondents were chosen using a simple random sampling method. The collected data were analyzed by Cobb-Douglas production function, economic analysis by calculating the returm to scale value, and farmer income analysis. The results showed that the factors that affected the production of lowland rice was land size, seeds, NPK fertilizer, pesticide, and labour. The use of production factors were not efficient because it was classified to increasing return to scale. The income earned by the farmers over the total cost was IDR24,636,334.99 with R/C value of 3.89 and it was profitable.
\end{abstract}

Key words: efficiency, income, production, lowland rice.

\section{PENDAHULUAN}

Salah satu komoditas tanaman pangan yang paling banyak diusahakan di Indonesia adalah padi. Tanaman ini merupakan komoditas utama yang berperan sebagai pemenuh kebutuhan karbohidrat bagi penduduk Indonesia. Setiap tahunnya kebutuhan padi di Indonesia mengalami peningkatan akibat dari pertambahan jumlah penduduk yang besar, serta berkembangnya industri pangan dan pakan (Yusuf 2010).

Sejalan dengan meningkatnya jumlah penduduk dan pendapatan penduduk, maka kebutuhan beras akan terus meningkat. Untuk mengantisipasi peningkatan kebutuhan beras tersebut, maka produksi padi harus semakin ditingkatkan dengan laju yang tinggi pula, agar kebutuhan beras dapat terpenuhi. Namun pada kenyataannya, laju pertumbuhan padi tidak selalu dapat terealisasi, karena banyak faktor yang menyebabkan peningkatan produksi mengalami kendala.

Provinsi Sumatera Utara merupakan salah satu wilayah di Indonesia yang menghasilkan padi dan termasuk ke dalam sentra produksi padi di Indonesia yang menempati urutan ke-6 tertinggi dilihat dari luas panen dan produksi padi pada tahun 2015. Namun apabila dilihat dari produktivitasnya, Provinsi Sumatera Utara masih tergolong rendah yaitu 5,17 ton/ha. Salah satu sentra produksi beras di Sumatera Utara yang memiliki lahan yang tergolong subur adalah Kabupaten Toba Samosir. Kabupaten Toba Samosir menempati peringkat pertama dalam produktivitas padi di Provinsi Sumatera Utara pada tahun 2016 (BPS 2017).

Menurut BPS Provinsi Sumatera Utara (2018), Kecamatan Balige merupakan salah satu sentra produksi padi di Kabupaten Toba Samosir dan tercatat sebagai daerah yang memiliki luas panen dan produksi tertinggi. Namun demikian, produktivitas Kecamatan Balige (yaitu 6,07 ton/ha) masih lebih rendah dibandingkan dengan produktivitas Kabupaten Toba Samosir (yaitu 6,47 ton/ha). Hal ini diduga berkaitan dengan penggunaan faktor produksi yang belum optimal. Produksi yang rendah akan mengakibatkan produktivitas rendah dan pendapatan petani menjadi rendah.

Berdasarkan uraian sebelumnya, maka tujuan penelitian ini adalah mengidentifikasi faktor-faktor produksi yang mempengaruhi produksi padi di Kecamatan Balige, menganalisis efisiensi produksi padi di Kecamatan Balige, dan menganalisis pendapatan usahatani padi di Kecamatan Balige. 


\section{METODE PENELITIAN}

Penelitian dilaksanakan di Kecamatan Balige Kabupaten Toba Samosir dengan metode survei. Penentuan lokasi penelitian dilakukan secara sengaja (purposive) dengan pertimbangan bahwa Kecamatan Balige merupakan salah satu sentra produksi padi sawah di Kabupaten Toba Samosir. Pengambilan data dilakukan di 2 (dua) desa, yaitu Desa Hutagaol Peatalun dan Desa Hinalang Bagasan, dengan pertimbangan bahwa ke dua desa tersebut merupakan sentra produksi padi sawah di Kecamatan Balige (BPS Kabupaten Toba Samosir 2018). Pengumpulan data dilaksanakan pada bulan April-Mei 2019.

Jenis data yang digunakan dalam penelitian ini adalah data primer dan sekunder. Data primer diperoleh dari petani responden (dengan teknik wawancara menggunakan kuesioner) dan pengamatan di lapangan. Data sekunder diperoleh dari berbagai literatur, laporan atau artikel yang berkaitan dengan penelitian.

Responden di daerah penelitian adalah petani padi sawah. Berdasarkan BP3K Kecamatan Balige (2017) diketahui bahwa jumlah populasi petani yang mengusahakan padi sawah di desa penelitian adalah 350 kepala keluarga. Sampel penelitian dihitung menggunakan rumus Sugiarto, Sunaryanto, dan Oetomo (2003), sehingga diperoleh jumlah sampel sebanyak 63 orang terdiri dari 39 orang di Desa Hutagaol Peatalun dan 24 orang di Desa Hinalang Bagasan. Selanjutnya, sampel diambil dengan metode Simple Random Sampling.

Fungsi produksi Cobb-Douglas digunakan untuk menganalisis faktor-faktor yang mempengaruhi produksi padi sawah. Secara matematis, fungsi produksi Cobb-Douglas dirumuskan sebagai (Soekartawi 2003) :

$\mathrm{Y}=\mathrm{b}_{0} \mathrm{X}_{1}{ }^{\mathrm{bi}} \mathrm{X}_{2}^{\mathrm{b} 2} \mathrm{X}_{3}{ }^{\mathrm{b} 3} \mathrm{X}_{4}{ }^{\mathrm{b} 4} \mathrm{X}_{5}{ }^{\mathrm{b} 5} \mathrm{X}_{6}{ }^{\mathrm{b} 6} \mathrm{X}_{7}{ }^{\mathrm{b} 7} \mathrm{X}_{8}{ }^{\mathrm{b} 8} \mathrm{X}_{9}{ }^{\mathrm{b} 9} \mathrm{e}^{\mathrm{u}} \ldots$

Fungsi produksi Cobb-Douglas dapat ditransformasikan ke dalam bentuk logaritma natural untuk mempermudah analisis, menjadi :

$\operatorname{Ln} Y=\operatorname{Ln} b_{0}+b_{1} \operatorname{Ln} X_{1}+b_{2} \operatorname{Ln} X_{2}+b_{3} \operatorname{Ln} X_{3}+$ $b_{4} \operatorname{Ln} X_{4}+b_{5} \operatorname{Ln} X_{5}+b_{6} \operatorname{Ln} X_{6}+b_{7} \operatorname{Ln} X_{7}$ $+b_{8} \operatorname{Ln} X_{8}+b_{9} \operatorname{Ln} X_{9}+e^{u}$.

Keterangan :

bo $=$ Intersep

bi $\quad=$ Koefisien regresi penduga variabel ke-i (i $=1,2, \ldots . ., 9$ )
$\mathrm{Y}=$ Produksi yang dihasilkan (kg GKP)

$\mathrm{X} 1=$ Luas lahan (ha)

$\mathrm{X} 2=$ Benih $(\mathrm{kg})$

$\mathrm{X} 3=$ Pupuk NPK $(\mathrm{kg})$

$\mathrm{X} 4=$ Pupuk Urea $(\mathrm{kg})$

$\mathrm{X} 5=$ Pupuk SP $36(\mathrm{~kg})$

$\mathrm{X} 6=$ Pupuk ZA $(\mathrm{kg})$

$\mathrm{X} 7 \quad=$ Pupuk organik $(\mathrm{kg})$

$\mathrm{X} 8=$ Pestisida $(\mathrm{gr} \mathrm{ba})$

X9 = Tenaga kerja (HOK)

$\mathrm{n} \quad=$ Jumlah faktor produksi

$\mathrm{e} \quad=2.7182$ (bilangan natural)

$\mu \quad=$ Tingkat kesalahan

Efisiensi produksi (secara ekonomi) terjadi apabila efisiensi teknis dan efisiensi harga tercapai dan memenuhi dua kondisi, yaitu :

a. Syarat keharusan, proses produksi harus berada pada daerah II, yaitu pada tingkat efisiensi $0<\mathrm{Ep} \leq 1$. Hal tersebut menunjukkan efisiensi produksi secara teknis.

b. Syarat kecukupan (sufficient condition) adalah kondisi keuntungan maksimum tercapai dengan syarat nilai produk marginal (NPM) sama dengan biaya korbanan marginal (BKM). Hal ini menunjukkan efisiensi harga (Soekartawi 2002).

Syarat keharusan dianalisis dengan mengetahui return to scale (RTS). Pengujian return to scale menggunakan rumus:

$\operatorname{RTS}=\beta_{1}+\beta_{2}+\beta_{3}+\beta_{4}+\ldots \ldots+\beta_{\mathrm{n}}$

Keterangan:

RTS = Skala produksi usahatani padi sawah (return to scale)

$\beta_{(1,2 \ldots \mathrm{n})}=$ Koefisien regresi variabel input

Kemungkinan terdapat tiga alternatif RTS, yaitu :

a. Decreasing return to scale, bila $\Sigma \beta \mathrm{i}<1$, dapat diartikan sebagai proporsi penambahan produksi lebih kecil dari proporsi penambahan faktor produksi.

b. Constant return to scale, bila $\Sigma \beta \mathrm{i}=1$, dapat diartikan sebagai proporsi penambahan produksi sama dengan proporsi penambahan faktor produksi.

c. Increasing return to scale, bila $\Sigma \beta \mathrm{i}>1$, dapat diartikan sebagai proporsi penambahan produksi lebih besar dari proporsi penambahan faktor produksi.

Efisiensi harga terjadi apabila nilai produk marginal sama dengan harga faktor produksi yang bersangkutan (Soekartawi 2003). Dalam kondisi 
demikian, maka NPM sama dengan harga faktor produksi dan dapat dirumuskan sebagai berikut:

$\frac{\text { bi.Y.Py }}{\text { Xi.Pxi }}=1$ atau $\frac{\text { NPM }}{P x}=1$

Keterangan:

Px = Harga faktor produksi $\mathrm{x}$

$\mathrm{bi}=$ Parameter regresi

Y = Jumlah output

Py = Harga output

Menurut Soekartawi (2003), NPM tidak selalu sama dengan Px, sehingga menyebabkan kondisi:

a. NPM/Px > 1, artinya penggunaan input $\mathrm{X}$ belum efisien, agar mencapai efisien, maka input $\mathrm{X}$ perlu ditambah.

b. NPM/Px $<1$, artinya penggunaan input $\mathrm{X}$ tidak efisien, agar mencapai efisien, maka input $\mathrm{X}$ perlu dikurangi.

Pendapatan usahatani adalah selisih antara total penerimaan dengan biaya (Soekartawi 2002). Keuntungan dapat dirumuskan sebagai berikut:

$$
\begin{aligned}
\pi & =\mathrm{TR}-\mathrm{TC} \\
& =\mathrm{Y} \cdot \mathrm{Py}-\Sigma \mathrm{Xi} . \text { Pxi }
\end{aligned}
$$

Keterangan:

$\pi \quad=$ Pendapatan (Rp)

$\mathrm{TR}=$ Total revenue $(\mathrm{Rp})$

$\mathrm{TC}=$ Total cost $($ total biaya) $(\mathrm{Rp})$

$\mathrm{Y}=$ Jumlah produksi $(\mathrm{kg})$

Py = Harga satuan produksi (Rp)

$\mathrm{Xi}=$ Faktor produksi ke-i (unit)

Pxi $=$ Harga faktor produksi (Rp/unit)

$\mathrm{i}=1,2,3, \ldots \ldots, \mathrm{n}$

Usahatani yang menguntungkan atau tidak dapat dianalisis dengan menggunakan nisbah antara penerimaan total dan biaya total yang disebut dengan Revenue Cost Ratio ( $R / C$ Ratio), dan dirumuskan sebagai berikut:

$\mathrm{R} / \mathrm{C}$ Ratio $=\frac{\mathrm{TR}}{\mathrm{TC}}$.

Keterangan:

$\begin{array}{ll}\text { R/C Ratio } & =\text { Rasio penerimaan dan biaya } \\ \mathrm{TR} & =\text { Total revenue } \\ \mathrm{TC} & =\text { Total cost }(\text { total biaya) }\end{array}$

Kriteria pengambilan keputusannya adalah:

a. Jika R/C $>1$, maka usahatani yang dilakukan menguntungkan.

b. Jika $\mathrm{R} / \mathrm{C}=1$, maka usahatani yang dilakukan berada pada titik impas (break even point). c. Jika $\mathrm{R} / \mathrm{C}<1$, maka usahatani yang dilakukan tidak menguntungkan.

\section{HASIL DAN PEMBAHASAN}

Tingkat pendidikan petani padi sawah di Kecamatan Balige relatif sudah tinggi, dimana persentase pendidikan tertinggi adalah tamatan SLTA $(71,88 \%)$. Rata-rata petani padi sawah di Kecamatan Balige berpengalaman usahatani selama 14 tahun dengan pengalaman usahatani maksimum selama 25 tahun dan pengalaman usahatani minimum selama 7 tahun dengan mayoritas $(73,44 \%)$ petani berpengalaman usahatani pada interval 10-20 tahun. Rata-rata jumlah tanggungan keluarga petani usahatani padi sawah di Kecamatan Balige adalah 5 orang dengan tanggungan keluarga terbesar adalah 9 orang dan terkecil adalah 1 orang dengan mayoritas $(76,56 \%)$ petani memiliki tanggungan keluarga pada interval 4-6 orang.

\section{Penggunaan Faktor Produksi dan Produksi Padi Sawah}

Lahan merupakan tempat berlangsungnya proses produksi. Luas lahan dapat mempengaruhi besarnya pendapatan usahatani. Rata-rata luas lahan pada usahatani padi sawah di Kecamatan Balige Kabupaten Toba Samosir adalah 0,76 ha dengan luas lahan terbesar adalah 1,70 ha dan terkecil adalah 0,23 ha. Mayoritas $(79,69 \%)$ petani padi sawah di Kecamatan Balige memiliki lahan $0,50-1$ ha dengan status milik sendiri. Penggunaan faktor-faktor produksi padi sawah di Kecamatan Balige Kabupaten Toba Samosir dapat dilihat pada Tabel 1. Benih padi sawah yang digunakan petani adalah varietas 100 hari, varietas Sibolga dan varietas boru Pardede. Penggunaan benih padi rata-rata per hektar adalah $80 \mathrm{~kg}$.

Tabel 1. Penggunaan faktor-faktor produksi padi sawah di Kecamatan Balige per ha pada musim tanam I, tahun 2019

\begin{tabular}{lrr}
\hline \multicolumn{1}{c}{ Jenis input } & $\begin{array}{c}\text { Jumlah per } \\
\text { ha }\end{array}$ & $\begin{array}{c}\text { Anjuran per } \\
\text { ha }\end{array}$ \\
\hline Benih & 86,79 & 80,00 \\
Pupuk NPK (kg) & 105,78 & 150,00 \\
Pupuk Urea (kg) & 270,53 & 350,00 \\
Pupuk SP-36 (kg) & 101,50 & 120,00 \\
Pupuk ZA (kg) & 61,78 & - \\
Pupuk Organik (kg) & 20,81 & 25,00 \\
Matador (gr bahan aktif) & 20,61 & - \\
Antrakol (gr bahan aktif) & $1.289,65$ & - \\
Dursban (gr bahan aktif) & 170,82 & - \\
Tenaga Kerja (HOK) & 99,03 & - \\
\hline
\end{tabular}


Petani padi sawah di Kecamatan Balige menggunakan lima jenis pupuk, yaitu pupuk NPK, pupuk Urea, pupuk SP 36, pupuk ZA dan pupuk organik. Hama dan penyakit yang menyerang padi sawah di Kecamatan Balige adalah wereng, ulat, hawar daun, dan penyakit kresek. Jenis pestisida yang paling banyak digunakan oleh petani adalah pestisida dengan merk dagang Matador, Antrakol dan Dursban. Tenaga kerja yang digunakan dalam usahatani padi sawah dikelompokkan menjadi tenaga kerja dalam keluarga dan tenaga kerja luar keluarga. Tenaga kerja dalam keluarga yang digunakan untuk luasan lahan 0,76 ha adalah 21,95 HOK, tenaga kerja luar keluarga sebanyak 39,90 HOK dan mesin sebesar 13,34 HOK.

Hasil produksi total yang diperoleh pada usahatani padi sawah di Kecamatan Balige Kabupaten Toba Samosir pada musim tanam I adalah $8.332,37 \mathrm{~kg}$ GKP per ha. Hasil produksi dari total produksi sebagian besar dijual, yaitu 5.244,70 kg GKP $(62,94 \%$ dari total produksi) dan sisanya dikonsumsi, yaitu 3.087,67 kg GKP (37,06\% dari total produksi). Produksi yang dikonsumsi di Kecamatan Balige tergolong besar dan berbeda dengan penelitian Dunan (2017) tentang analisis faktor produksi terhadap pendapatan petani padi sawah dengan sistem PTT di Kelurahan Naga Huta Kecamatan Siantar Marimbun, dimana seluruh hasil produksi langsung dijual dan tidak ada yang dikonsumsi sendiri.

\section{Faktor-faktor yang Mempengaruhi Produksi}

Fungsi produksi Cobb-Douglas digunakan untuk menganalisis faktor-faktor yang mempengaruhi produksi padi sawah. Faktor-faktor produksi yang diduga mempengaruhi produksi padi sawah (Y) di Kecamatan Balige Kabupaten Toba Samosir adalah luas lahan $\left(\mathrm{X}_{1}\right)$, benih $\left(\mathrm{X}_{2}\right)$, pupuk NPK $\left(\mathrm{X}_{3}\right)$, pupuk urea $\left(\mathrm{X}_{4}\right)$, pupuk SP $36\left(\mathrm{X}_{5}\right)$, pupuk ZA $\left(\mathrm{X}_{6}\right)$, pupuk organik $\left(\mathrm{X}_{7}\right)$, pestisida $\left(\mathrm{X}_{8}\right)$ dan tenaga kerja $\left(\mathrm{X}_{9}\right)$. Dari Tabel 2 diketahui bahwa nilai VIF setiap variabel bebas lebih kecil dari 10 (VIF $<10)$, sehingga model pendugaan faktor-faktor yang mempengaruhi produksi padi sawah di Kecamatan Balige tidak ada multikolinearitas. Selain itu, dilakukan uji heteroskedastisitas menggunakan uji White dan diperoleh nilai Prob Chi-square > 0,05 (0,1732), sehingga tidak ada heteroskedastisitas. Nilai koefisien determinasi $\left(\mathrm{R}^{2}\right)$ didapat sebesar 97,30 persen dengan nilai koefisien determinasi terkoreksi (Adjusted $R^{2}$ ) sebesar 96,80 persen.
Tabel 2. Hasil pendugaan koefisien faktor-faktor yang mempengaruhi tingkat produksi padi sawah di Kecamatan Balige pada musim tanam I, tahun 2019

\begin{tabular}{|c|c|c|c|c|}
\hline Variabel & $\begin{array}{c}\text { Koef. } \\
\text { Regresi }\end{array}$ & t-hitung & Sig. & VIF \\
\hline Konstanta & 5,318 & 12,063 & 0,000 & \\
\hline Ln L.Lahan $\left(\mathrm{X}_{1}\right)$ & $0,361 * * *$ & 4,843 & 0,000 & 9,998 \\
\hline $\operatorname{Ln} \operatorname{Benih}\left(\mathrm{X}_{2}\right)$ & $0,157 * * *$ & 2,973 & 0,004 & 5,667 \\
\hline Ln p. NPK $\left(\mathrm{X}_{3}\right)$ & $0,185 * * *$ & 2,832 & 0,006 & 7,515 \\
\hline Ln p. Urea $\left(\mathrm{X}_{4}\right)$ & 0,038 & 0,929 & 0,357 & 5,314 \\
\hline Ln p. SP 36 (X5) & 0,001 & 1,081 & 0,284 & 1,296 \\
\hline Ln p. ZA $\left(\mathrm{X}_{6}\right)$ & 0,068 & 1,635 & 0,108 & 2,970 \\
\hline Ln p. Organik $\left(\mathrm{X}_{7}\right)$ & $0,099 *$ & 1,946 & 0,057 & 5,461 \\
\hline Ln Pestisida $\left(\mathrm{X}_{8}\right)$ & $0,129 * * *$ & 3,221 & 0,002 & 2,793 \\
\hline Ln T. Kerja $\left(X_{9}\right)$ & $0,099 * *$ & 2,125 & 0,038 & 2,688 \\
\hline F-hitung & 215,956 & & 0,000 & \\
\hline$R^{2}$ & 0,973 & & & \\
\hline Adjusted- $R^{2}$ & 0,968 & & & \\
\hline \multicolumn{5}{|l|}{ Keterangan: } \\
\hline $\begin{array}{ll}* * * & : \text { Nyata pada } \\
* * & : \text { Nyata pada } \\
* & \end{array}$ & $\begin{array}{l}\text { kat kepercas } \\
\text { kat kepercay }\end{array}$ & $\begin{array}{l}\text { aan } 99 \% \\
\text { aan } 95 \% \\
\text { agn } 90 \%\end{array}$ & & \\
\hline
\end{tabular}

Nilai koefisien determinasi $\left(\mathrm{R}^{2}\right)$ tersebut berarti bahwa sebesar 97,30 persen dari variasi produksi dapat dijelaskan secara bersama-sama oleh faktor luas lahan, benih, pupuk NPK, pupuk Urea, pupuk SP 36, pupuk ZA, pupuk organik, pestisida, dan tenaga kerja, sedangkan sisanya $(2,70 \%)$ dipengaruhi oleh faktor- faktor lain di luar model. Nilai uji F-hitung sebesar 215,956 yang signifikan pada taraf kepercayaan 99 persen, yang berarti bahwa faktor-faktor produksi yang digunakan secara bersama-sama nyata berpengaruh terhadap produksi padi sawah di Kecamatan Balige.

Persamaan regresi faktor-faktor yang mempengaruhi usahatani padi sawah di Kecamatan Balige dapat dirumuskan sebagai berikut:

$$
\begin{aligned}
\mathrm{Y}= & 187,59 \mathrm{X}_{1}{ }^{0,361} \mathrm{X}_{2}{ }^{0,157} \mathrm{X}_{3}{ }^{0,185} \mathrm{X}_{4}{ }^{0,038} \\
& \mathrm{X}_{5}^{0,000} \mathrm{X}_{6}{ }^{0,068} \mathrm{X}_{7}{ }^{0,099} \mathrm{X}_{8}^{0,129} \mathrm{X}_{9}^{0,099} \mathrm{e}^{\mathrm{u}} \ldots(7) \\
\text { sehingga, } & \\
\text { Ln Y }= & 5,318+0,361 \operatorname{LnX}_{1}+0,157 \operatorname{LnX}_{2}+ \\
& 0,185 \operatorname{LnX} X_{3}+0,038 \operatorname{LnX}_{4}+0,001 \\
& \operatorname{LnX}_{5}+0,068 \operatorname{LnX}_{6}+0,099 \operatorname{LnX}_{7}+ \\
& 0,129 \operatorname{LnX}_{8}+0,099 \operatorname{LnX}_{9}+\mu \ldots \ldots .(8)
\end{aligned}
$$

Setelah uji F, dilakukan pula uji-t untuk menguji penduga faktor-faktor yang mempengaruh produksi padi sawah di Kecamatan Balige. Dari Tabel 2 diketahui bahwa terdapat beberapa faktor produksi yang berpengaruh nyata terhadap produksi padi sawah, yaitu luas lahan, benih, pupuk NPK, pupuk organik, pestisida, dan tenaga kerja, dan sisanya yaitu pupuk urea, pupuk SP36, dan pupuk ZA tidak berpengaruh nyata terhadap produksi padi sawah di Kecamatan Balige. 
1. Luas lahan berpengaruh nyata terhadap produksi padi sawah pada tingkat kepercayaan 99 persen. Nilai elastisitas lahan adalah 0,361 yang menunjukkan bahwa setiap penambahan lahan sebesar 1 persen, maka akan meningkatkan produksi sebesar 0,361 persen dengan asumsi faktor produksi lainnya tidak berubah (ceteris paribus).

2. Benih berpengaruh nyata terhadap produksi padi sawah pada tingkat kepercayaan 99 persen. Nilai elastisitas benih adalah 0,157 yang berarti setiap penambahan benih 1 persen akan menambah hasil produksi padi sawah sebesar 0,157 persen dengan asumsi faktor produksi lainnya tidak berubah.

3. Pupuk NPK berpengaruh nyata terhadap produksi padi sawah pada tingkat kepercayaan 99 persen. Nilai elastisitas pupuk urea adalah 0,185 menunjukkan bahwa setiap penambahan pupuk urea sebesar 1 persen akan menambah jumlah produksi padi sawah sebesar 0,185 persen dengan asumsi faktor produksi lainnya tidak berubah.

4. Pupuk organik berpengaruh nyata terhadap produksi padi sawah pada tingkat kepercayaan 90 persen. Nilai elastisitas pupuk urea adalah 0,099 menunjukkan bahwa setiap penambahan pupuk urea sebesar 1 persen akan menambah jumlah produksi padi sawah sebesar 0,099 persen dengan asumsi faktor produksi lainnya tidak berubah.

5. Pestisida berpengaruh nyata terhadap produksi padi sawah dengan tingkat kepercayaan 99 persen. Nilai elastisitas pestisida adalah 0,129 menunjukkan bahwa setiap penambahan pestisida sebesar 1 persen akan menambah jumlah produksi padi sawah sebesar 0,129 persen dengan asumsi faktor produksi lainnya tidak berubah.

6. Tenaga kerja berpengaruh nyata terhadap produksi padi sawah dengan tingkat kepercayaan 95 persen. Nilai elasitisitas tenaga kerja sebesar 0,099 menunjukkan bahwa setiap penambahan tenaga kerja sebesar 1 persen akan menambah jumlah produksi padi sawah sebesar 0,099 persen dengan asumsi faktor produksi lainnya tdak berubah.

Hasil penelitian ini sejalan dengan penelitian Hadiana (2017) tentang efisiensi faktor produksi dan pendapatan usahatani padi sawah dengan sistem bagi hasil di Desa Kirisik Kecamatan Jatinunggal Kabupaten Sumedang dan Laksmi, Suamba, dan Ambarwati (2012) tentang efisiensi usahatani padi sawah di Desa Subak Guama Kecamatan Marga Kabupaten Tabanan, dimana secara tunggal benih, pestisida, dan tenaga kerja, sedangkan faktor-faktor produksi luas lahan, pupuk NPK, dan pupuk organik dalam penelitian Hadiana (2017) dan Laksmi, Suamba, dan Ambarwati (2012) tidak nyata berpengaruh terhadap produksi padi sawah.

\section{Efisiensi Produksi Usahatani Padi Sawah}

Analisis efisiensi produksi usahatani padi sawah di Kecamatan Balige Kabupaten Toba Samosir dilakukan dengan menggunakan analisis efisiensi yang memenuhi dua syarat, yaitu syarat keharusan (Necessary Condition) dan syarat kecukupan (Sufficient Condition).

Syarat keharusan adalah usahatani padi sawah sudah efisien jika $0<\mathrm{Ep}<1$ dan return to scale berada pada daerah II, yakni $0<\mathrm{RTS}<1$. Return to scale diperoleh dari nilai $\Sigma \beta \mathrm{i}$. Syarat kecukupan adalah usahatani padi efisien jika NPM/BKM = 1 atau NPM=BKM. Syarat keharusan (RTS) harus diuji dengan uji skala usaha. Jika F-hitung $<$ F-tabel, maka skala usaha termasuk dalam constant return to scale. Apabila syarat keharusan telah terpenuhi, maka dilanjutkan dengan melihat analisis syarat kecukupan (pengujian NPM/BKM).

Nilai koefisien regresi $(\beta)$ seluruh faktor-faktor produksi dalam persamaan Cobb-Douglas menyatakan tingkat elastisitas produksi dari usahatani padi sawah. Jumlah koefisien $(\Sigma \beta \mathrm{i})$ adalah 1,03 yang menunjukkan bahwa elastisitas produksi padi sawah berada pada daerah I (Ep>1), sehingga dapat diartikan bahwa proporsi penambahan produksi lebih besar daripada proporsi penambahan faktor produksi (increasing return to scale). Selanjutnya, untuk memastikan posisi proses produksi padi sawah di Kecamatan Balige fit dalam kaidah increasing return to scale, dilakukan uji skala usaha.

Hasil uji skala usaha untuk return to scale disajikan pada Tabel 3. Dari Tabel 3 diketahui bahwa nilai F-hitung lebih besar dari F-tabel pada taraf nyata $\alpha=5$ persen dan $\alpha=10$ persen, sehingga tolak $\mathrm{H}_{0}$ yang berarti skala usaha pada usahatani padi sawah di Kecamatan Balige tidak dalam kondisi constant return to scale (CRS), sehingga syarat keharusan dalam analisis efisiensi produksi tidak terpenuhi. Syarat keharusan yang tidak terpenuhi mengindikasikan bahwa usahatani belum efisien secara ekonomi, sehingga analisis syarat kecukupan (NPM/BKM) tidak dilakukan (tidak dilanjutkan). 
Hasil penelitian ini sejalan dengan penelitian Lybaws, Alamsyah, dan Fitri (2017) tentang efisiensi ekonomi dan penggunaan faktor-faktor produksi pada usahatani padi ladang di Kecamatan Pauh Kabupaten Sarolangun dan penelitian Sinabariba, Prasmatiwi, dan Situmorang (2014) tentang efisiensi produksi dan pendapatan usahatani kacang tanah di Kecamatan Terbanggi Besar Kabupaten Lampung Tengah, dimana skala usaha penelitian tersebut juga berada pada increasing return to scale, sehingga dinyatakan bahwa usahatani belum efisien.

\section{Analisis Pendapatan Usahatani Padi Sawah}

Analisis pendapatan usahatani penting dilakukan untuk mengetahui dan memberikan gambaran mengenai keuntungan yang diperoleh dari kegiatan usahatani padi sawah. Analisis pendapatan usahatani meliputi pendapatan atas biaya tunai dan pendapatan atas biaya total. Komponen biaya yang dikeluarkan oleh petani terdiri dari biaya tunai dan biaya yang diperhitungkan.
Tabel 3. Pengujian skala usaha pada usahatani padi sawah di Kecamatan Balige, tahun 2019

\begin{tabular}{|c|c|c|c|c|}
\hline \multirow{2}{*}{ Hipotesis } & \multirow{2}{*}{$\begin{array}{c}\text { F- } \\
\text { hitung }\end{array}$} & \multicolumn{2}{|c|}{ F-tabel } & \multirow{2}{*}{ Keterangan } \\
\hline & & 0,05 & 0,10 & \\
\hline $\begin{array}{l}\mathrm{H}_{0}: \sum \mathrm{bi}=1 \\
(\mathrm{CRS}) \\
\mathrm{H}_{1}: \sum \mathrm{bi} \neq 1 \\
(\mathrm{IRS} / \mathrm{DRS})\end{array}$ & 15,65 & 2,98 & 2,32 & $\begin{array}{c}\text { F-hitung }>\mathrm{F}- \\
\text { tabel } \\
\left(\text { Tolak } \mathrm{H}_{0}\right)\end{array}$ \\
\hline
\end{tabular}

Biaya tunai terdiri dari biaya sarana produksi usahatani padi sawah yaitu benih, pupuk NPK, pupuk Urea, pupuk SP36, pupuk ZA, pupuk organik, pestisida dan biaya tenaga kerja luar keluarga. Biaya yang diperhitungkan terdiri dari biaya penyusutan peralatan, sewa lahan yang diperhitungkan, dan biaya tenaga kerja dalam keluarga yang telah dikonversi dengan upah tenaga kerja luar keluarga. Penerimaan usahatani pada penelitian ini diperoleh dari menghitung seluruh hasil produksi yang dihasilkan oleh petani responden per 0,76 ha dalam satu musim tanam dalam bentuk Gabah Kering Panen (GKP). Hasil analisis pendapatan usahatani padi di Kecamatan Balige tahun 2019 disajikan pada Tabel 4.

Tabel 4. Analisis pendapatan dan R/C Ratio usahatani padi sawah pada musim tanam I di Kecamatan Balige tahun 2019

\begin{tabular}{|c|c|c|c|c|c|c|}
\hline \multirow[b]{2}{*}{ No } & \multirow[b]{2}{*}{ Uraian } & \multicolumn{3}{|c|}{ Usahatani per $0,76 \mathrm{ha}$} & \multicolumn{2}{|c|}{ Usahatani per 1 ha } \\
\hline & & Jumlah & $\begin{array}{c}\text { Harga } \\
(\mathrm{Rp})\end{array}$ & $\begin{array}{c}\text { Nilai } \\
(\mathrm{Rp} / \mathrm{MT})\end{array}$ & Jumlah & $\begin{array}{c}\text { Nilai } \\
(\mathrm{Rp} / \mathrm{MT})\end{array}$ \\
\hline \multirow[t]{4}{*}{1} & Penerimaan (Produksi x Harga) & & & & & \\
\hline & Produksi yang dijual $(\mathrm{kg})$ & $3.981,88$ & $5.242,97$ & $20.876 .846,19$ & $5.244,70$ & $27.497 .801,12$ \\
\hline & Produksi yang dikonsumsi (kg) & $2.344,22$ & $5.242,97$ & $12.290 .665,65$ & $3.087,67$ & $16.188 .569,70$ \\
\hline & Total Penerimaan & $6.326,09$ & $5.242,97$ & $33.167 .511,84$ & $8.332,37$ & $43.686 .370,81$ \\
\hline \multirow[t]{20}{*}{2} & Biaya Produksi & & & & & \\
\hline & a. Biaya Tunai & & & & & \\
\hline & Pupuk NPK (kg) & 80,31 & $2.550,00$ & $204.796,88$ & 105,78 & $269.746,86$ \\
\hline & Pupuk Urea (kg) & 205,39 & $2.000,00$ & $410.781,25$ & 270,53 & $541.057,83$ \\
\hline & Pupuk SP-36 (kg) & 77,06 & $2.200,00$ & $169.537,50$ & 101,50 & $223.305,21$ \\
\hline & Pupuk ZA (kg) & 46,91 & $1.660,00$ & $77.864,38$ & 61,78 & $102.558,55$ \\
\hline & Pupuk Organik (kg) & 15,80 & $2.500,00$ & $39.492,19$ & 20,81 & $52.016,88$ \\
\hline & Pestisida: & & & & & \\
\hline & Matador (1) & 0,63 & $200.000,00$ & $125.187,50$ & 0,82 & $164.889,90$ \\
\hline & Antrakol (kg) & 1,40 & $100.000,00$ & $139.875,00$ & 1,84 & $184.235,44$ \\
\hline & Dursban (l) & 0,65 & $100.000,00$ & $64.843,75$ & 0,85 & $85.408,52$ \\
\hline & TKLK (HOK) & 53,23 & $70.000,00$ & $3.726 .347,66$ & 70,12 & $4.908 .134,39$ \\
\hline & Total Biaya Tunai & & & $4.958 .726,09$ & & $6.531 .353,57$ \\
\hline & b. Biaya Diperhitungkan & & & & & \\
\hline & TK Dalam Keluarga (HOK) & 21,95 & $50.000,00$ & $1.097 .363,28$ & 28,91 & $1.445 .384,85$ \\
\hline & Penyusutan Alat (Rp) & & & $84.334,67$ & & $111.080,86$ \\
\hline & Benih $(\mathrm{kg})$ & 65,89 & $19.000,00$ & $1.251 .921,88$ & 86,79 & $1.648 .960,69$ \\
\hline & Sewa Lahan (Rp) & 0,76 & $1.500 .000,00$ & $1.138 .828,13$ & & $1.500 .000,00$ \\
\hline & Total Biaya Diperhitungkan & & & $3.572 .447,95$ & & $4.705 .426,41$ \\
\hline & Total Biaya & & & $8.531 .174,05$ & & $11.236 .779,98$ \\
\hline \multirow[t]{2}{*}{3} & Pendapatan total atas biaya tunai & & & $28.208 .785,75$ & & $37.155 .017,24$ \\
\hline & Pendapatan total atas biaya total & & & $24.636 .337,79$ & & $32.449 .590,84$ \\
\hline \multirow[t]{2}{*}{4} & $\mathrm{R} / \mathrm{C}$ atas biaya tunai & & & 6,69 & & 6,69 \\
\hline & $\mathrm{R} / \mathrm{C}$ atas biaya total & & & 3,89 & & 3,89 \\
\hline
\end{tabular}


Berdasarkan Tabel 4 dapat diketahui bahwa produksi total padi sawah per 0,76 ha per musim tanam adalah $6.326 \mathrm{~kg}$ yang dibagi menjadi 2, yaitu dijual dan dikonsumsi sendiri. Jumlah yang dijual adalah $3.981,88 \mathrm{~kg}(62,94 \%$ total produksi) dan dikonsumsi sendiri sebesar $2.344,22 \mathrm{~kg}$ (37,06\% total produksi). Harga jual gabah kering panen yang berlaku di Kecamatan Balige adalah Rp5,243,00/kg sehingga penerimaan total usahatani padi sawah di Kecamatan Balige Kabupaten Toba Samosir per 0,76 ha per musim tanam adalah Rp33.167.511,84 terdiri dari penerimaan tunai sebesar $\mathrm{Rp} 20.876 .846,19$ dan penerimaan diperhitungkan sebesar Rp12.290.665,65.

Selanjutnya, dari Tabel 4 juga dapat diketahui bahwa pendapatan tunai usahatani padi sawah atas biaya tunai di Kecamatan Balige adalah Rp15.918.120,10 per 0,76 ha per musim, sedangkan pendapatan tunai atas biaya total adalah sebesar Rp12.345.672,14 per 0,76 ha per musim tanam. Pendapatan total petani padi sawah atas biaya tunai di Kecamatan Balige adalah $\mathrm{Rp} 28.208 .785,75$ dengan nilai $\mathrm{R} / \mathrm{C}$ ratio atas biaya tunai sebesar 6.69. Hal ini menunjukkan bahwa penggunaan biaya produksi tunai sebesar Rp1.000,00 akan menghasilkan penerimaan sebesar Rp6.690,00. Pendapatan total atas biaya total sebesar Rp24.636.337,79 per 0,76 ha per musim dengan nilai $\mathrm{R} / \mathrm{C}$ ratio sebesar 3,89 . Hal tersebut menunjukkan bahwa penggunaan biaya produksi total sebesar Rp1.000,00 akan menghasilkan Rp3.890,00.

Tabel 4 menunjukkan bahwa nilai $\mathrm{R} / \mathrm{C}$ ratio produksi padi sawah di Kecamatan Balige, baik atas biaya tunai maupun biaya total lebih besar dari 1, artinya usahatani padi sawah di Kecamatan Balige menguntungkan untuk diusahakan. Hasil penelitian ini sejalan dengan penelitian Noer, Zakaria, dan Murniati (2018) tentang analisis pendapatan dan efisiensi produksi usahatani padi ladang di Kecamatan Sidomulyo Kabupaten Lampung Selatan dan penelitian Handayani Effendi, dan Viantimala (2017) tentang produksi dan pendapatan usahatani di Desa Pujo Asri Kecamatatan Trimurjo Kabupaten Lampung Tengah yang menghasilkan $\mathrm{R} / \mathrm{C}$ ratio $>1$, yang berarti usahatani padi di daerah penelitian menguntungkan.

\section{KESIMPULAN}

Berdasarkan penelitian yang telah dilakukan dapat disimpulkan bahwa faktor-faktor yang mempengaruhi produksi padi sawah di Kecamatan Balige adalah luas lahan, benih, pupuk NPK, pupuk organik, pestisida, dan tenaga kerja. Proses produksi usahatani padi sawah belum efisien, karena masih berada pada increasing return to scale. Penggunaan faktor produksi perlu ditingkatkan, agar tercapai produksi yang optimum. Walaupun demikian, usahatani padi sawah di Kecamatan Balige Kabupaten Toba Samosir menguntungkan dengan nilai $\mathrm{R} / \mathrm{C}$ ratio lebih besar dari 1.

\section{DAFTAR PUSTAKA}

BPS [Badan Pusat Statistik] Jakarta. 2017. Konsumsi Beras Indonesia. https://www.bps.go.id. [4 Desember 2018].

BPS [Badan Pusat Statistik] Jakarta. 2018. Sebaran Luas Panen dan Produksi Berdasarkan Kecamatan di Toba Samosir. https://tobasamosirkab.bps.go.id/ publication/2017/09/25/05a41179742a34801b c003b3/kecamatan-balige-dalam-angka 2017.html. [18 Januari 2019].

BPS [Badan Pusat Statistik] Provinsi Sumatera Utara. 2017. Jumlah Produksi Padi di Indonesia 2016. https://www.bps.go.id/link TableDinamis/view/id/827. [5 Januari 2019].

BPS [Badan Pusat Statistik] Provinsi Sumatera Utara. 2018. Sebaran Luas Panen, Produksi dan Produktivitas Berdasarkan Kabupaten di Sumatera Utara. https://sumut.bps.go.id/ statictable/2017/11/20/765/luas-panenprodu ksi-dan-rata-rata-produksi-padi-sawah-20062016.html. [15 Desember 2018].

BP3K [Balai Penyuluhan Pertanian Perikanan dan Kehutanan] Kecamatan Balige. 2017. Kecamatan Balige Dalam Angka. Dinas Pertanian dan Perikanan. BP3K Kecamatan Balige. Toba Samosir.

Dunan HP. 2017. Analisis faktor produksi terhadap pendapatan petani padi sawah dengan sistem PTT. Jurnal Murni Sadar 62, 7 (1) : 62-77. http://murnisadar.ac.id/bundles/murnisadar/do wnloads/Analisis.Faktor.Produksi.Terhadap.P endapatan.Petani.Padi.Sawah.Dengan.Sistem. PTT.pdf. [25 Oktober 2019].

Hadiana D. 2017. Analisis efisiensi faktor produksi dan pendapatan usahatani padi sawah dengan sistem bagi hasil. Jurnai Ilmu Pertanian dan Peternakan, 5 (2) : 119-129. https://www.jurnal.unma.ac.id/index.php/AG/ article/viewFile/742/689. [4 Oktober 2019].

Handayani SA, Effendi I, dan Viantimala B. 2017. Produksi dan pendapatan usahatani padi di Desa Pujo Asri Kecamatan Trimurjo Kabu 
paten Lampung Tengah. Jurnal Ilmu Ilmu Agribisnis,5(4):422-429.

http://jurnal.fp.unila.ac.id/index.php/JIA

/article/download/1752/1555

Laksmi NMAC, Suamba IK dan Ambarawati IGAA. 2012. Analisis efisiensi usahatani padi sawah. Jurnal Agribisnis dan Agrowisata, 1 (1) : 34-44. Error! Hyperlink reference not valid.. [4 Oktober 2019].

Lybaws DF, Alamsyah Z dan Fitri Y. 2017. Analisis efisiensi ekonomi penggunaan faktorfaktor produksi pada usahatani padi ladang di Kecamatan Pauh Kabupaten Sarolangun. Skripsi. Error! Hyperlink reference not valid. [4 Oktober 2019]

Maulidiah. 2012. Pengantar Usahatani: Kelayakan Usahatani. Lab of Agribusiness Analysis ang Management Faculty of Agriculture. Universitas.Brawijaya. Malang

Noer SC, Zakaria WA, dan Murniati K. 2018. Analisis efisiensi produksi usahatani padi ladang di Kecamatan Sidomulyo Kabupaten Lampung Selatan. Jurnal Ilmu Ilmu Agribisnis, $\quad$ 6(1) :17-24. http://repository.lppm.unila.ac.id/9287/1/2492 -5874-1-SM.pdf [7 Oktober 2019].

Sinabariba FM, Prasmatiwi FE, dan Situmorang S. 2014. Analisis efisiensi produksi dan pendapatan usahatani kacang tanah di Kecamatan Terbanggi Besar Kabupaten Lampung Selatan. Jurnal Ilmu Ilmu Agribisnis, $\quad 2$ (4): 316-322. http://jurnal.fp.unila.ac.id/index.php/JIA/articl e/download/985/891. [4 Oktober 2019].

Soekartawi. 1993. Prinsip Dasar Agribisnis: Teori dan Aplikasinya. PT. Raja Grafindo Persada. Jakarta.

Soekartawi. 2002. Prinsip Dasar Ekonomi Pertanian Teori dan Aplikasi. PT. Raja Grafindo. Jakarta.

Soekartawi. 2003. Teori Ekonomi Produksi Dengan Pokok Bahasan Analisis Fungsi Cobb-Douglas. PT. Raja Grafindo Persada. Jakarta.

Sugiarto DS, Sunaryanto LT, dan Oetomo DS. 2003. Teknik Sampling. Gramedia. Jakarta.

Yusuf A. 2010. Teknologi Budidaya Padi Sawah Mendukung SI-PTT. BPTP. Sumatera Utara. 